\title{
YO NO SIGO AL ROMÁNTICO PEDANTE. GUILLERMO MATTA Y EL CASO DE LA POLÍTICA ROMÁNTICA EN CHILE PARA MEDIADOS DE SIGLO XIX
}

Yo no sigo al romántico pedante. Guillermo Matta and the case of romantic politics in Chile for the mid-nineteenth century

\author{
CLAUDIO VÉlIZ ROJAS \\ Universidad de los Andes (Chile) \\ cveliz@uandes.cl \\ SEBASTIÁN GUTIÉRREZLILLO \\ Universidad Central de Chile (Chile) \\ sebastian.gutierrez@ucentral.cl
}

Resumen

El siguiente trabajo pretende analizar la categoría de "romanticismo político" desarrollada por el filósofo alemán Carl Schmitt, aplicando su acepción de "política romántica" al caso del poetapolítico chileno Guillermo Matta Goyenechea (1829-1889). Por medio de términos tales como imaginación, lenguaje cósmico, progreso moral, democracia, entre otros, este poeta-político articuló su discurso social durante el periodo de 1853 a 1858, como elementos de disputa con el poder regente bajo la intención de reformar la sociedad chilena de su época.

Palabras claves: Romanticismo político; Chile; siglo XIX.

\section{Abstract}

The present work had the purpose of defining the category of "political romanticism" developed by the German philosopher Carl Schmitt, applying its meaning of "romantic politics" to the case of the Chilean political poet Guillermo Matta Goyenechea (1829-1889). Through the terms stories such as imagination, cosmic language, moral progress, democracy, among others, this poetpolitician articulated his social discourse during the period from 1853 to 1858 , as elements of dispute with the ruling power under the intention of reforming the chilean society of his time.

Key words: Political romanticism; Chile; 19th century.

\section{VIEJAS PERSPECTIVAS, NUEVAS REFLEXIONES}

Si bien el estudio del término de romanticismo se ha realizado mediante múltiples escritos que lo comprenden en su variante literaria, sociológica e histórica, según comprendemos, el estudio de Carl Schmitt ha sido uno de los pocos, sino el único, que ha pretendido establecer las raíces del concepto desde un sustrato filosófico político. $\mathrm{Su}$ obra Romanticismo político, texto publicado en 1919 y que solo fue rescatado para una versión en castellano para el 2005, corresponde una aproximación teórica al estudio del desarrollo del romanticismo político alemán por medio de la trayectoria y los escritos del 
intelectual decimonónico Adam Müeller. En dicho estudio, Schmitt intenta demostrar la existencia del romanticismo político bajo un específico concepto: la ".....ocassio...". Refiriéndose al "ocasionalismo" de esta práctica, Schmitt argumenta:

El hecho de que una voluntad política importante y que debe tomarse en serio solo puede imputar a un objeto ocasional da al suceso su estructura romántica (...) un conjunto de fuertes energías políticas no es capaz de encontrar su objetivo y golpea con gran ímpetu un punto ocasional (Schmitt, [1919] 2005, p. 223).

Para Schmitt, el romanticismo posee una indefinición que lo permea frente a la crítica, tentando - muchas veces lográndolo-a los investigadores para entender el término por sus características más que por un concepto definido. El romántico, según Schmitt, utiliza la realidad como un medio para el despliegue de su producción artística. A su vez, la presencia de una burguesía que optó por un punto medio en la salida política al conflicto bipolar de su nación y la actitud permanentemente estética del sujeto que de forma constante está romantizando la esfera política, son dos elementos que nos entrega el análisis de Schmitt para apreciar esta primerísima definición de romanticismo político, la que podría tener un cierto lugar al interior de nuestras fronteras.

Un acertado prólogo a la primera edición en castellano del filósofo argentino Jorge Dotti, nos invita a un interesante cuestionamiento del devenir del concepto en América Latina durante el siglo XIX. Al interior de este prefacio, el investigador plantea la posible existencia de políticos románticos latinoamericanos, en confrontación al romanticismo político, suponiendo esta idea a partir de los postulados que Schmitt habría delegado para una fracción de la aristocracia alemana del siglo XIX. Según Schimtt: "hay que diferenciar claramente los casos de romanticismo político de los de política romántica. Un hombre que no es esencialmente romántico puede estar motivado por representaciones romantizadas y poner su energía, que surge de otras fuentes, al servicio de aquellas" (Schmitt, [1919] 2005, p. 223). Esta potencial propuesta, según Dotti, invertiría la tesis principal de Schmitt toda vez que Esteban Echeverría, Juan Bautista Alberdi y otros intelectuales de la mencionada generación, actuarían en oposición al romanticismo político criticado por Schmitt. Este grupo de avanzada objetualizaría los elementos propios de cierto romanticismo europeo impactando un punto ocasional de su contexto, pero sin dejarse absorber por el concepto en tanto utilización del mundo como oportunidad para su propia producción artística. Las ideas político románticas de esta generación actuarían como un acérrimo compromiso con su contexto cultural en el que el romanticismo, específicamente su variante francesa, les abrirían el paso para el conocimiento del mundo y la posibilidad de transformarlo (Tarcus, 2016, p. 15).

Dicho punto, a nuestro juicio, sería una entrada a la forma en que se habrían desarrollado los políticos románticos en nuestro país durante el siglo XIX. ¿De qué forma? Un conjunto de hombres que haciendo suyo el discurso romántico contenido en 
Yo no sigo al romántico pedante. Guillermo Matta y el caso de la política romántica en Chile

las literaturas europeas, utilizó dichos objetos poniéndolos al servicio de sus planes políticos reformadores.

\section{MATTA,LAS POESÍAS YLAPOLÍTICA.TRAZADODEUNATRAYECTORIAPOLÍTICO-ROMÁNTICA}

Guillermo Matta Goyenechea nació en Copiapó en 1829, en el seno de una familia protoburguesa minera. Estudió humanidades en el Colegio de Santiago dirigido por José María Núñez, para posteriormente rendir sus exámenes en el Instituto Nacional (Amunátegui Solar, 1915, p. 334). Al interior de este emblemático establecimiento, Matta cursó estudios de literatura, filosofía, derecho constitucional, economía política y derecho internacional (Figueroa, 1897, p. 284). En 1853 abandona la empresa minera familiar para abocarse en tiempo completo al cultivo de la poesía. En el periodo de 1853 a 1858, el escritor participó activamente en el desarrollo del panorama cultural chileno: publicó en las revistas y periódicos de la época como La Sílfide (1853), El Museo (1853), La Revista de Santiago, segunda época (1855), El Correo Literario (1858), entre otras. Entre 1859 y 1861 el poeta parte al exilio debido a la condena impuesta por el gobierno de Manuel Montt.

La obra lírica de Guillermo Matta ha sido destacada por variados autores contemporáneos a su época y de mayor actualidad, como un conjunto de textos profundamente influenciada por escritores europeos de la época. José de Espronceda, Lord Byron, así como diversos autores alemanes como Heinrich Heine, August Schiller, Wolfgang Goethe, entre otros (Lillo, 1853, pp. 204-207; Miguel Luis Amunátegui, 1861, pp.358-388; Ramírez Cortés, 1862, pp. 2-51; Amunátegui Solar, 1915, pp. 320-341; Dussuel, 1959, pp. 252-255; Promis 1975, pp. 12-15; Nómez 2000, pp. 60-63).

El ingreso del escritor al mercado cultural chileno es avalado por la aparición de su primer libro de poesías titulado Cuentos en verso (1853). Publicando dos poemas narrativos que imitaron en estilo a las composiciones de Lord Byron y Espronceda, la obra de Matta despertó una gran conmoción en el pequeño escenario de la época y, sin duda, se constituyó como una afrenta a los sectores más conservadores de la sociedad chilena. La Revista Católica, órgano de la Iglesia Católica en Chile para la época, tildó la publicación abiertamente de satánica (Pena, 1985, p. 408). Ahora bien, en el prefacio mismo de la obra, materia que es de nuestro interés, el autor indicaba lo siguiente:

Había pensado en escribir un largo prólogo y aún tenía parte trabajado, sobre esta carencia de melodías que se nota en nuestra sociedad, sobre esa preocupación añeja que se allega a todo lo que es poesía, pero después he pensado que quizás no era este el lugar más a propósitos y me he decidido a abandonar ese trabajo molesto, para hacer algunas indicaciones, solamente a aquellos que guardan en su alma esa chispa celeste, ese sentimiento armonioso que se llama poesía y que es el lenguaje del corazón y la palabra luminosa del universo (Matta, 1853, p. v). 
Esta presunta crítica al problema de los espacios para el desarrollo de las artes, que luego repliega su discurso en torno a una definición tentativa de poesía, constituye un primer llamado desde la función literaria hacia la esfera político-social. La denuncia de Matta frente a un mercado que no está preparado para el despliegue de su obra, podríamos interpretarlo como uno de los grandes hitos que colaborarían en la conformación del futuro campo literario chileno. Como medio y espacio, el poeta opone a la realidad del contexto nacional, la emancipación trascendental del lenguaje del corazón y la palabra luminosa del Universo que sobrevuele el referente real y lo atraviesa. En dicho sentido, Matta estaría aplicando uno de los vectores que, según Roger Picard, pertenecen al romanticismo social francés. En Picard, el romanticismo se entrega absolutamente a "la religión del corazón": son las pasiones y el corazón lo que permitiría luchar contra el egoísmo de la sociedad (Picard, [1944] 2005, pp. 39-40). A su vez, la alusión del texto acerca del afán universalista de la poesía, palabra luminosa nada menos que del "universo", también formaría parte de los parámetros definidos por la escuela romántica francesa. De acuerdo con el citado especialista, el poeta romántico busca ser la representación de un amplio grupo. Poesía tentativamente social, el lírico escapa del egoísmo y apela a su contacto con la divinidad para canalizar por medio de él, una guía efectiva hacia la libertad absoluta (Picard, [1944] 2005, pp. 40-41). Ambos irracionales, ambos trascendentes, estos puntos de conexión entre el yo poético y el mundo, son utilizados para referir al contexto de emergencia del texto.

Prosiguiendo nuestro análisis del mismo prefacio, el autor desarrolla la explicación de su proyecto a partir de otros elementos icónicos del romanticismo como es la historia y la poesía como profecía de los pueblos:

Por poco que se conozca la historia de los pueblos, en todo se verá el influjo poderoso que la poesía ha ejercido, en sus creencias, en sus costumbres y en sus tendencias, civilizadoras del porvenir. Y más de una vez sus audaces pensamientos han sido sublimes profecías, estrellas vivas en la noche de los tiempos que los hombres han visto realizadas como por encanto. Esa poesía, es el pensamiento divino, es la segunda vista de la humanidad; y esa poesía no podrá morir; porque el pensamiento no muere y porque no puede apagarse el sol del alma, por más que sus detractores quieran oscurecerlo (Matta, 1853, p. vi).

La definición de la poesía como luz de la humanidad, comunicación divina y en forma de visión profética de los pueblos, son perspectivas respecto del arte que fueron tomados durante el siglo XIX, sobre todo por la escuela del romanticismo alemán. Novalis, Herder, los hermanos Schlegel, mediante sus distintos tratados de estética y poesía, dibujaron la figura de una literatura que estaba destinada a emancipar al hombre y que presentaba particularmente al poeta, como el vicario de la voz divina. El símbolo de la poesía como una voz que debía liberar al hombre impulsa a los poetas a tomar posiciones políticas, creyendo en los inicios de la revolución francesa, para luego terminar 
frustrados por sus consecuencias. La poesía y las artes representan en el romanticismo alemán, una capacidad creadora absoluta, desde la que estos artistas son auténticos comunicadores de un mundo que está más allá del entendimiento humano (Hausser, [1950] 1993,pp. 339-362). Asimismo, el romanticismo social francés también utilizó una visión parecida en sus poetas y novelistas. Esta visión dotaba a sus portadores de una visión suprema que avizoraba el futuro y actuaba como representante de una entidad natural guía de civilizaciones. La labor de la poesía se presenta como un componente notablemente social pues conecta al arte con la comunidad, para fungirse como el representante de la misma y de su historia (Picard, [1944] 2005, pp. 70-71). Siendo la poesía representante del puente entre la imaginación y las anticipaciones del espíritu, el poeta se vio como un iluminado de su tiempo, que debía ejercer como guía moral de la sociedad (Picard, [1944] 2005, pp. 40).

Si bien las estéticas presentadas por las primeras composiciones de Matta exhiben una ilación que está plagada por elementos románticos, estas no se despegan de su contexto político. Lo anteriormente dicho es evidenciado con la siguiente cita:

Nosotros no tenemos poesía tradicional, toda nuestra tradición es una guerra sanguinaria y terrible; no tenemos sociedad; porque apenas es una farsa; no tenemos educación por el arte, que la ignorancia no comprende; y por eso la gente entregada a su egoísmo particular y enteramente extraña a ese lenguaje palpitante de la naturaleza, trata de desechar esa poesía civilizadora y altipoesía, como un contrasentido social (Matta, 1853, p. vii).

Puntos interesantes en este fragmento. El autor niega la posibilidad de una poesía que se haya instaurado antes de la época que, según comprendemos, él está fundando. La historia nacional al ser sanguinaria y terrible habría impedido la germinación de unos pilares que avalen la elevación de otro escenario que no sea la esterilidad a la que el poeta se siente llamado a criticar. De esta forma, el autor vendría a inaugurar un ideal de belleza que no estaría presente en el contexto nacional. Arrogándose el privilegio de fundar la tradición poética, Matta se posiciona una vez más, como el vicario de un mensaje trascendente al que se ve empujado, para reformar la sociedad. A su vez, la acusación de la farsa social se presenta del todo atingente al gobierno en el que emerge la obra. Declaradamente liberal junto a gran parte de su grupo intelectual, el prefacio de Matta ataca sin un nombre preciso a esta sociedad que se está formando. La sociedad chilena aludida por el poeta se constituye en un signo vacío de contenido. En el curso lógico de su discurso, podríamos inferir que la farsa está dada por un grupo que continúa en la tradición hispana conservadora, profesando un republicanismo sin praxis. El ataque, entendemos, fue contra Manuel Montt.

La falta de educación en el arte, por otro lado, conducirían en el análisis del autor hacia el exacerbado egoísmo y la apatía social. Siguiendo el contenido del enunciado, solo la educación en las artes permitiría la creación de una comunidad, que remitiera una vez 
más a un estado primordial de naturaleza. El estado de naturaleza como un estado en que el hombre expresa su bondad fuera de la corrupción social alude a otro de estos objetos románticos que utilizados por el autor develan su pensamiento político literario. La poesía, bajo esta premisa, sería la herramienta de este lenguaje que le es extraño a una sociedad egoísta: una sociedad que, por su alejamiento de este lenguaje de naturaleza, se aleja a su vez, de la civilización que trae en su palabra la poesía. A este respecto, al tratar el tema de la búsqueda de la verdad en el romanticismo social francés, Picard postula dicha relación, romanticismo y naturaleza, como un elemento vinculante y distintivo de la práctica líricasocial del movimiento. Para el crítico, la naturaleza representaría en el movimiento romántico francés la intuición de la realidad, siendo un elemento de inspiración absoluta (Picard, [1944] 2005, pp. 40). Como ya lo hemos indicado, para Matta el lenguaje primordial está inscrito en la naturaleza y es el apartamiento de la sociedad de este vínculo, la naturaleza, la que los empujaría al error y la indiferencia social.

A modo de cierre a este interesante manifiesto romántico de la poesía chilena, Matta declara:

Cuentos de pura imaginación, hablan más a ella que a el alma. La imaginación es la favorita de la juventud y esta se goza en caminar con ella por los campos floridos; y ellas cogen espinas que la hagan llorar, la poesía reúne esas lágrimas tiernas para exhalarlas en un perfume de armonía (Matta, 1853, p. vii).

El final de este prefacio es construido claramente sobre uno de los puntos que más ataca Schmitt en el romanticismo alemán, y que más asume nuestro autor para argumentar su calidad poética. Es la imaginación, según Schmitt, la que abre el paso para el escapismo del romanticismo político, toda vez que frente a la indefinición de una realidad ante la que no puede lidiar el sujeto romántico, utiliza esta puerta para mantener su juicio en suspenso y no decidirse ante la cuestión política (Schmitt, [1919] 2005, p. 60). Por otra parte, bajo el análisis de Picard, la imaginación se presenta como un elemento de gran relevancia para la variante social del romanticismo francés. De acuerdo con el especialista, la imaginación ayudó a los poetas y novelistas franceses a descubrir la verdad y construir el bien social de la época. Esto, debido a su ilimitada capacidad de abrir amplias expectativas al espíritu, en dominios inexplorables para racionalidad del clasicismo (Picard, [1944] 2005, pp. 37). En el caso de Matta, es la imaginación el punto de contacto en que las juventudes pueden experimentar de la mano del corazón, la transformación de su emocionalidad en poesía. La imaginación, bajo este sentido, conecta a la juventud como parte de un mundo en que desaparece el referente real y solo restaría la emocionalidad de los corazones destilados por la poesía.

Otro tanto podemos decir de su próximo trabajo Napoleón El Chico (1854). Esta traducción del conocido escritor francés Víctor Hugo, fue publicada en 1854 y abrió la ocasión a nuestro autor para manifestar su parecer ante la situación política francesa, así como exponer una crítica solapada al gobierno chileno en ejercicio. Siendo una obra literaria 36 | Alpha № 52 (JuLIO 2021) PÁGS. 31-42. ISSN 07 16-4254 
emanada de un reconocido representante del romanticismo social francés decimonónico, nuestras preguntas las orientamos a las decisiones de Matta en torno al texto. 1) ¿Cuál fue la intención de Matta por traducir específicamente esta obra de Víctor Hugo para el año de 1854 ? y 2) ¿Cuál fue la necesidad de colocar un prefacio de su propia iniciativa, que antecediera la obra de Víctor Hugo? Desde un juego cooperativo entre la obra traducida y el ideario defendido, no podemos soslayar el hecho de que para el propio escritor francés, el romanticismo no fuese otra cosa que el liberalismo en la literatura (Víctor Hugo, [1830] 1971, pp. 3-4). Esta cita nos recuerda la finalidad política de la literatura en Víctor Hugo, para quien las obras son medios de difusión de sus ideas, armas para abatir el enemigo político del pueblo (Picard, [1944] 2005, p. 111).

Es importante recordar que para 1854 el gobierno de Manuel Montt está en su apogeo y con él, la gran oposición liberal comienza a levantarse en busca de la segunda oportunidad para el grupo liberal. Montt representa el bastión del conservadurismo político y el grupo de Matta, Gallo y otros liberales, lo fijarán como su objetivo a derrocar por distintos medios. La alusión a Napoleón El Chico -que no disfraza la figura de Luis Bonaparte, por cierto-, encuentra su símil americano en la figura del opositor político representado por Montt. Por otro lado, Matta pone en circulación su propio parecer acerca de la relevancia del texto, pero con una doble intención que es, pensamos, poner a disposición del público, sus propias ideas políticas ante la situación de la contingencia chilena.

Defendiendo esta vez los conceptos de democracia, revolución y progreso, Matta en A propósito de Napoleón el Chico, declaraba lo siguiente:

Toda revolución es un nuevo desarrollo, una nueva manifestación de la verdad; es un mundo de ignorancia que cae y otro que se levanta; en una palabra, es la inauguración de una idea más grande y la exaltación de un principio más noble. Para que un hombre pueda ser representante de esa idea tan compleja como grandiosa, es necesario que se afirme en la fuerza del pueblo que es la libertad, y en el pensamiento de ese pueblo que es la democracia. Es necesario que ese hombre aleje al pasado con sus preocupaciones, con sus odios, para fundar el porvenir sin los escombros de aquel (Matta, 1854, p. v).

De esta forma, el autor explica los principios operantes en los que debe funcionar una revolución haciendo énfasis, en que esta debe ser avalada por otros conceptos mayores tales como democracia y libertad. Idea grandiosa y compleja -al momento no notamos negatividad en el término- la revolución debe estar guiada por un pueblo que la avale y una libertad que la acompañe. Revolución, idea, democracia, libertad y pueblos, bajo esta lógica, si bien son conceptos que forman parte del repertorio lingüístico americano, puestos en realce por Matta y asociados a la figura de Víctor Hugo, son términos constituyentes de un lenguaje propiamente político-romántico. Matta reconoce su trayectoria intelectual, así como el mismo contexto europeo en que los hechos narrados 
por el vate francés tienen su lugar. Democracia, por ejemplo, está sostenida por el apoyo popular y se exhibe como la representación de las libertades en un plano extenso que no reconoce límites. Apoyando este postulado, Roger Picard sostiene que son los grandes poetas franceses del romanticismo social quienes divulgan este sentido, como la gran misión de poeta. Esta misión está avalada por "un socialismo humanitario, una filosofía social apoyada en las nociones de justicia, de progreso y de libertad" (Picard, [1944]2005, pp. 51). Como podemos apreciar, estos conceptos -justicia, progreso y libertad-tienen su equivalente en el plano discursivo de Matta. Asumidos desde un referente similar, no olvidemos que la excusa para hablar de Montt es Luis Bonaparte, el prefacio de Matta amplifica el significado de este sistema para su aplicación a la escena nacional chilena.

Acerca de lo ya mencionado, el autor continúa en el desglose del término con la siguiente premisa: "Cada revolución ha tenido por cuna a un gran pueblo; y en cada una de sus representantes han sido los hombres de la abnegación, los hombres del sacrificio, los hombres del pensamiento popular y no los de la tradición caduca" (Matta, 1854, pp. v-vi). Matta vuelve a la justificación de la revolución apoyada esta vez en un líder que sea reconocido por sus valores personales, sacrificio y abnegación, así como por una sólida base popular. La mención de lo popular y la revolución, también corresponden a reconocidos elementos valiosos al discurso romántico, en el que el pueblo representa la encarnación de la esencia nacional y, la revolución, se lee como un medio eficaz para conseguir la realización del cambio necesario. Tanto en el análisis de Arnold Hausser como en el de Roger Picard, la imagen de la revolución francesa está directamente vinculada al origen del romanticismo. En sus variadas repercusiones por Europa, la revolución francesa se presenta como la fisura hacia el canon de la Ilustración y el Clasicismo, en una lucha permanente por la libertad en diversos ámbitos. Como ya hemos revisado, en el caso del romanticismo social francés, la vinculación del poeta como guía de pueblo es particularmente fuerte (Hausser [1950] 1993, p. 326: Picard [1944] 2005, p. 111).

Para el 1857, Matta ya plenamente integrado en la arena política y literaria chilena, expondrá otro objeto romántico como es la fraternidad. Ante la invasión de William Walker a Nicaragua, el poeta es uno de tantos intelectuales americanos que se levantó en protesta para reclamar por la acción imperialista de EE. UU. En su poema "A América" (1857), Matta increpa la incursión filibustera de Walker, en búsqueda de la reacción de América:

¡América! ¡despierta! Reúne tus banderas

Con todas ellas forma sagrado pabellón;

Y suene por montañas, por bosques y riberas,

Un grito -dos palabras- ¡Fraternidad y Unión!.. ([1857] 1889, p. 9).

Este fragmento que se reiterará en dos ocasiones a lo largo del poema expone con claridad el americanismo del autor, así como la utilización de dos términos que forman 38 | Alpha № 52 (JuLIO 2021) PÁGS. 31-42. ISSN 07 16-4254 
parte de su ideario político romántico. La unión y la fraternidad americana, para este caso, constituyen puntos capaces de sostener la arquitectura de la respuesta ante la invasión colonizadora. Como bien reconocemos, los términos de unión y, particularmente de fraternidad, son conceptos asociados generalmente, a la revolución francesa. Estos ideales fueron asumidos con prontitud por el romanticismo social francés, como elementos discursivos para trabajar en la transformación de las desigualdades sociales. De acuerdo con Picard: "Para los románticos es indudable que toda su época procede de 1789 y no vacilan en afirmarlo en público y ante auditorios más moderados" (Picard, [1944] 2005, p. 332). Ambos términos ponen en evidencia el fuerte compromiso del autor hacia el mundo que habita, separándose de esta falta de decisión que aludía Schmitt con los románticos políticos, al establecer una condena directa ante EE. UU. y sus afanes colonizadores. No obstante, y como punto relevante en esta discusión, la condena de Matta no se dirige tan solo, contra Estados Unidos sino contra todo poder que intente subyugar a América. En una significativa nota a pie de página dispuesta por el autor para 1863 y recuperada en ediciones posteriores, Matta apela a la actualidad de las poesías ante situaciones particulares, y actualiza el contenido de su canto para señalar que "Walker y sus filibusteros, Napoleón III y sus secuaces se diferencian únicamente en los nombres; pero el crimen es el mismo" ([1863] 1889: pp. 1-2). Frente a esta amenaza en que "el crimen es el mismo" pero el perpetrador podría cambiar, la unión y la fraternidad americana deberán alzarse. A este respecto, el texto de Matta señalaría evidencia de política romántica en los términos explicados por Schimtt, vale decir, "un conjunto de fuertes energías políticas no es capaz de identificar su objetivo y golpea con gran ímpetu un punto ocasional" (Schmitt [1919], 2005, p. 223).

Lejos del modelo del arte por el arte, el discurso político se hace necesario para Matta, pero sin abandonar los objetos románticos que permiten el acceso mediatizado en la escena política. La definición de la poesía en la sociedad chilena (1853), la promoción política de una obra literaria del romanticismo francés (1854) así como la generación de un poema abiertamente político americano (1857), constituyen parte de un discurso de que en Matta se harán cuerpo y este cuerpo, marchará directamente el gobierno.

La participación de Matta para 1858 es un hecho que incluyó la performance del ciudadano en abierta oposición al gobierno de Manuel Montt. Como muestra de ello, el periódico La Asamblea Constituyente se forjó con un solo objetivo: era la formación de la asamblea constituyente o, bien, la caída del gobierno. En 13 números, a 2 columnas, este periódico político que reunió entre sus redactores a la familia Matta y Gallo, también fue medio para que el joven de 24 años, Guillermo Matta, tentase la vía del discurso político directo. Respaldando la apelación para una asamblea constituyente, Matta escribió para el sábado 4 de diciembre de 1858 el editorial "Nuestra situación política":

Qué quieren decir este despertamiento uniforme, esta cruzada de porvenir, que se levanta en todos los pueblos de la República, en nombre de la justicia, en nombre 
de la libertad? Todo eso significa que marchamos, todo eso significa que una fuerza interior nos empuja irresistiblemente hacia otras sendas; todo eso significa que el espíritu de progreso, el espíritu de la vida, circula en la atmósfera de nuestra agitación, para ayudar a las grandes ideas que traen las transformaciones políticas (Matta 1858, p. 89).

Artilugio retórico en el discurso, lo dispuesto por Matta toma la forma de consulta para definir el estado de avance o retroceso que habría generado el gobierno durante esta época. La pregunta por el ¿"qué quieren decir"?, es una estrategia para explicar el significado de la situación política desde la individualidad del poeta político. Matta, profeta de la tempestad, se arroga el poder de la interpretación popular como ya lo hemos visto presente en el romanticismo de la época, para fungir como el vicario de estas señales que solo él, ante este panorama, puede explicar a los pueblos. Despertar, porvenir, pueblos, República, justicia y libertad, son conceptos utilizados por Matta para sustentar su discurso en un campo semántico que pareciera llamar a la revolución pero que esta vez, tan solo busca la reforma. La justicia y la libertad, conceptos tan caros al discurso político nacional, son utilizados por este ropaje retórico que recrea el movimiento de las mareas (despertar, levantar) porque es una fuerza interior que empuja al discurso y a los hombres para la concreción del espíritu de progreso. El progreso, equiparado a la vida, se distingue en los ojos del orador, en todos los rincones de la República. El concepto de "progreso" será tratado en Matta tanto en su base material, la definición del término en condición del avance tecnológico, como también por su vertiente espiritual, es decir, el concepto como sinónimo del 'optimismo social' al que propendería la sociedad. En relación con este mismo punto, Picard nos advierte que el concepto de progreso aplicado al caso de los románticos franceses busca reemplazar la Providencia por dicho término. Esto es, ya que el orden social no ha sido dado de una y definitiva vez, la realidad puede ser cambiada, en este sentido, la perfectibilidad puede ser alcanzada por vías humanas. Identificando el corazón del romanticismo bajo la figura del liberalismo (Picard, [1944] 2005, pp. 55-56), los conceptos de libertad, justicia y progreso, forman un sistema conceptual que se solidifica al interior del movimiento romántico.

Sumando argumentos para evaluar la situación política, el texto finaliza con un llamado del autor para todos los hombres dignos de la República:

Lo repetimos, nuestra bandera es la bandera de la República, la bandera de la patria, la única santa, la única justa! Ella nos debe guiar a la conquista de la libertad, de la justicia, derramando la luz y la verdad en todas las encrucijadas de la ambición y en todos los desvíos del pueblo. Y cuando el poder nos amenace, cuando el poder quiera invadir nuestras libertades, por la razón y la fuerza, despreciaremos esas amenazas y defenderemos esas libertades, por la razón y el derecho, con fe en las ideas, con fe en nuestro país! (Matta, 1858, p. 90). 
Mediante la utilización de los símbolos que invocan la autoridad de las ideas, el autor da a conocer sus respaldos, afianzados en la bandera de la Patria-República, como la única santa, la única justa. Apelar a la santidad de la causa, es un aspecto del discurso romántico que en el caso de Matta se exhibe y que se conduce por medio del concepto del derecho. En ese sentido, el significado extendido por el texto se encuentra con un poder que está más allá del entendimiento racional como es el patriotismo, pero enfilado por un derecho que según informa, ha sido uno de los grandes problemas de la administración de Montt. La oposición al poder de la fuerza se da en este párrafo, bajo el aspecto nominal del derecho, amparándose en elementos para superar la racionalidad de los juicios humanos. Poeta y representante del malestar social, Matta cierra su discurso invocando la fe en las ideas y el derecho como únicas armas legítimas, ante el arrasador poder del gobierno.

\section{CONCLUSIONES}

El número trece del periódico invitaba a todos sus lectores para reunirse en son de protesta contra el gobierno, para que este declarase una asamblea constituyente nacional. El gobierno de Montt, ante dicho petitorio, respondió con fuerza clausurando este periódico, encarcelando a sus cabecillas, así como a posterior, cerrando gran parte de los medios opositores (Collier, 2005). Guillermo Matta, Benjamín Vicuña Mackenna, Isidoro Errázuriz, Manuel Antonio Matta, serán llevados a juicio y condenados a pena de muerte. Esta decisión será cambiada en el transcurso del juicio, bajo la opción de que los líderes intelectuales del movimiento partan al exilio (Figueroa, 1897, p. 286). El poeta solo podrá regresar a Chile en 1861 bajo la ley de amnistía otorgada por el gobierno de Joaquín Pérez Mascayano.

En este sentido, el discurso de Guillermo Matta desarrollado entre el periodo de 1853 a 1858 se nos presenta en total compromiso con su propuesta política romántica. Desde conceptos claves como imaginación, lenguaje universal, en que el poeta se presenta como un guía del pueblo, el autor no cesó de establecer su crítica a su contexto, poniendo su propia vida en peligro efectivo. Términos como democracia, revolución, justicia, derecho, causa justa, fueron desarrollados por Matta bajo la firme convicción de que, sin importar el enemigo político, el progreso debía regenerar la estructura obsolescente que comenzó a mostrar en el decenio de Montt.

Asimismo, su performance de vate político fue profundamente influenciada por figuras como Víctor Hugo, quienes no solo extendieron sus enunciados para favorecer el escenario político de su contexto, sino que funcionaron como verdaderos representantes populares para lograr la anhelada transformación de la sociedad. El acto de consagración de Matta, bajo esta lógica, ya no estuvo dado exclusivamente por la aclaración de conceptos desde una perspectiva escapista, por la lucha desde la prensa o por una producción artística determinada. La consecuencia a sus acciones fue la condena a muerte 
y el posterior exilio que debió padecer al enfrentarse a una situación en la que su exaltación política tuvo un respaldo minoritario y poco significativo.

El epíteto de "liberalismo rojo" al que se aludiría a posterior (Gazmuri, 1999, p. 121), tendrá sentido en la puesta en escena del poeta político Matta. A favor de la democracia, en lucha contra lo que identificó como tiranía, desde una determinada producción artística, profeta del pueblo, impulsando la fraternidad americana en favor del progreso como espíritu de vida, Guillermo Matta fue un político romántico más que un romántico político para el Chile de mediados de siglo XIX.

\section{OBRAS CITADAS}

Amunátegui, Miguel Luis y Gregorio, Víctor (1861). Juicio crítico de algunos poetas hispanoamericanos. Santiago: Editorial Del Ferrocarril.

Amunátegui Solar, Domingo (1915). Bosquejo histórico de la literatura chilena. Santiago: Imprenta Universitaria.

Collier, Simon (2005). Chile: La construcción de una república 1830-1865. Santiago: Universidad Católica de Chile.

Dussuel Díaz, Francisco (1959). Literatura chilena. Vol. I. Santiago: Ediciones Paulinas.

Figueroa, Pedro (1897). Diccionario Biográfico de Chile. Santiago: Imprenta y Encuadernación Barcelona.

Gazmuri, Cristián (1999). El "48” chileno. Igualitarios, reformistas, masones y bomberos. Santiago: Editorial Universitaria.

Hausser, Arnold (1993). Historia social de la literatura y el arte. Vol. II. Barcelona: Editorial Debate.

Hugo, Victor (1971). Manifiesto romántico. Barcelona: Ediciones Península.

Lillo, Eusebio (1853). "Crítica Literaria. El cuento endemoniado". El Museo. Periódico Científico literario. Santiago: Imprenta Chilena. 3 de septiembre de 1853, 204-207.

Matta, Guillermo (1858). La Asamblea Constituyente. Nuestra situación política. Periodico 04 de Diciembre 1858, Santiago, Chile.

— (1854). "A propósito de Napoleón el Chico". Hugo, Víctor (1854). Napoleón El Chico. Santiago: Imprenta Chilena.

_ (1853). Cuentos en verso. Santiago: Imprenta de Santiago.

Nómez, Naín (2000). Antología crítica de la poesía chilena. Vol. I. Santiago: LOM.

Pena, Marta (1985). Romanticismo y política. Bs. As.: Ediciones Docencia.

Picard, Roger (2005). El romanticismo social. México DF.: Fondo de Cultura Económica.

Promis, José (1975). Poesía romántica chilena. Santiago: Editorial Nacimiento.

Ramírez Cortés, Mariano (1862). Juicio crítico de las poesías de Guillermo Matta. Santiago: Imprenta del Ferrocarril.

Schmitt, Carl (2005). Romanticismo político. Bs. As.: Universidad Nacional de Quilmes. Tarcus, H. (2016). El socialismo romántico en el Rio de la Plata (1837-1852). Bs. As.: FCE. 